\title{
The Use of Cinema to Prevent Cyberbullying
}

\author{
Syifa Nabila*, Sri Rahayu Nengsih and Andre Julius
}

\author{
Department of Guidance and Counselling, Ma'soem University, Indonesia \\ *Corresponding author. E-mail: syifanabila173@gmail.com
}

\begin{abstract}
Cyberbullying is a challenge for counselors in the face of the industrial revolution 4.0. Many studies report cyberbullying is the impact of the use of emerging technologies. The rise of cyberbullying affects mental, psychological and social disorders. This paper aims to formulate the prevention of cyberbullying using cinema. Based on the results of the study the prevention of cyberbullying using cinema is a preventive effort through the suppression of empathy. The use of cinema focuses on four aspects, namely intellectual, social, behavior, and emotional. Operationally, cyberbullying prevention using cinema follows the steps of cinema therapy, namely the brief, film selection, and home assignments.
\end{abstract}

Keywords: Cyberbullying, Cinema, psychological

\section{INTRODUCTION}

Cyberbullying is a threat in the era of social media, which contributes to mental, psychological, and social disorders. Ditch The Label's British Anti-bullying organization's survey of 10,020 respondents aged between 12 and 20 showed that Instagram was the first highest verbal violence in 2017 and Facebook became social media with the second-highest verbal violence Verbal violence in this context is better known as cyberbullying [1]. Cyberbullying can be negative comments on certain posts, unfriendly personal messages, and spreading posts or profiles of certain social media accounts by making fun of them.

UNICEF found that $50 \%$ of 41 teenagers in Indonesia between the ages of 13 and 15 have experienced cyberbullying. Some of these actions are publishing the personal data of others, stalker or stalking (stalking in cyberspace resulting in real-world stalking), and revenge in the form of uploading photos or videos with the aim of revenge coupled with acts of intimidation and extortion [2]. Cyberbullies use various information technology tools to carry out their actions. Social networks (35\%) and text messages (SMS) (33\%) ranked first and second as widely used means for cyberbullying [3]. Many studies have stated that cyberbullying is a negative impact of the openness of technology and information.

This is a challenge for counselors in the face of the industrial revolution 4.0 counselors. School counselors should be able to keep up with every development of the times, required to be more professional in conducting guidance and counseling. Counselors are expected to have media literacy understanding of various appropriate and relevant media. Media literacy is knowledge about how media works, how media builds social meanings and how media functions in our daily lives. The aim is to educate the public to be able to use the media intelligently and critically [4].

Based on media literacy studies, the use of cinema can prevent cyberbullying. The function of the cinema in addition to presenting information, can also influence attitudes, and motivate students gradually for the better. A cinema can improve students' understanding and independence to change their condition that originally had a poor social ethic for the better [5]. The use of cinema can help students reflect on the events surrounding it, concerning the importance of tolerance in creating peace [6].

The role of cinema in the prevention of cyberbullying is to stimulate the empathy of cyberbullies. Baron \& Byrne state that cinema can have a positive effect of increasing the growth and insight of students about empathy, they will feel empathy for the fictitious character as to the victim in real life [7]. Research shows at low affective empathy, both boys and girls who also had low cognitive empathy had higher scores on cyberbullying than those who had high cognitive empathy. This pattern of results was similarly found for boys with high affective empathy [8]. Empathy is an important aspect that students must have to prevent cyber bullying.

Therefore in this paper will describe how the use of cinema can prevent cyber bullying through the development of empathy. The paper is based on previous relevant studies and research on the origin of cyber bullying, how empathy can prevent cyber bullying, and how cinema can improve 
student's empathy. At the end of the paper will be illustrated a flow diagram of the use of cinema in preventing cyber bullying.

\section{METHODOLOGY}

The research method used is Library Research by analyzing theories about the concept of cinema therapy and cyberbullying. Data retrieved using data from primary and secondary sources. The primary source is a source directly related to the theme of research, namely the concept of cinema therapy and cyberbullying, which is taken from books and journals 10 years ago, accredited, and often cited by other authors. Secondary source is a supporting source in the $\mathrm{n}$ research that proves the effectiveness of cinema therapy.

\section{RESULTS AND DISCUSSION}

\subsection{The Origin of Cyberbullying}

Cyberspace gives Internet users the opportunity to attack other individuals: people known only from the Internet, celebrities, teachers, totally unknown individuals or whole groups of people. Involvement in such actions brings suffering to those victimized as well as potential negative consequences for the perpetrators [9]. Cyberbullying is an act that is continuously repeated through the use of computers, mobile phones, or other electronic devices to harm and hurt others [10].

Based on research Machimbarrena et al.[11] The biggest risk of internet abuse in adolescents is cyberbullying of $30.27 \%$. In the study, cyberbullying got the most percentage compared to other negative impacts. cyberbullying is one of the causes of internet abuse from social media among teenagers [12] . Interactions on social media can be done without having to be face-to-face and can also interact with known and unknown people.

Technology and information are not the only causes of cyberbullying. Cyberbullying is a teenager's decisionmaking in interacting and commenting on social media. Also, cyberbullying is understood to be aggressive behavior in adolescents through digital technology. Various psychological aspects cause cyber bullyings such as self-regulation, empathy, emotional maturity, and others. Empathy has a very close correlation with prosocial behavior. Students can share their feelings with others in an atmosphere of joy and sorrow, willingness to assist others both material and moral, and also willingness to work with others to achieve a goal. Empathy can also increase an individual's self-esteem.

The negative relationship between aggressive behavior and empathy is evident in various literature studies. Empathy is the ability to understand and share the feelings of others. Based on theoretical considerations, suggesting that a lack of responsive empathy may be characteristic of cyberbullies. Cyberbullies are found to be less empathic than their non-cyberbully counterparts. A research conducted for modeling predictors and consequences of cyberbullying found that empathy is one of the predictors. Although another study conducted in Singapore showed that cognitive empathy plays a crucial role in cyberbullying behavior, it also found that both cognitive and affective empathy play a vital role on cyberbullying [8]

Therefore, cyberbullying prevention interventions not only focus on regulating the use of gadgets and social media but develop students' ability to wisely social media. Empathy is the psychosocial capital of students to be wise in social media and avoid cyberbullying. The negative relationship between aggressive behavior and empathy is evident in various literature studies. Empathy is the ability to understand and share the feelings of others. Based on theoretical considerations, suggesting that a lack of responsive empathy may be characteristic of cyberbullies.

\subsection{Cinema as media to improve an emphaty}

Empathy is required for a deep understanding of the human condition. One of the advantages of cinema is that it gives a deep impression, which can affect students' attitudes[13]. The use of cinema is considered effective in increasing students' social sensitivity.

Cinema is useful in teaching empathy because it is familiar and evocative. Movies provide a quick and direct teaching scenario in which specific scenes point out important issues, emotions are presented in accessible ways where they are easy to identify, and learners are able to understand and recognize them immediately. In addition, learners have the opportunity to "translate" movie life histories into their own lives [14] .

The use of cinema in increasing empathy is grouped in four levels, namely intellectual, social, behavioral, and emotional. The four levels are depicted in the Table 1[15].

Table 1 Stages of cinema use in increasing empathy

Getting knowledge about behaviors that can solve problems, help self understanding, and gain intellectual

Intellectual insights

Broaden one's view of the different human conditions so as to obtain insight into the diversity of values considered valuable to humans.

Social Students can hone their social sensitivities. Students can feel the misery of a particular group/person

Behavior Gain the confidence to talk about difficult issues to discuss due to feelings of fear, shame, and guilt

Emotional Develop awareness emotional insights and 
increased empathy that leads to the ability to understand the feelings of others, listen carefully to what others are telling.

At an individual intellectual level reflect story content. Through cinema stories students identify themselves with characters and events in cinema, whether realer fictional, analyzing moral values, stimulating critical thinking, developing self-awareness, improving self-concept and improving personal and social judgment. The result is improved behavior, the ability to deal with and understand important life problems and increased empathy, tolerance and respect for others.

In social level, cinema can strengthen social patterns, culture, absorb the value of humanity and have each other. Cinema encourages students' morals centered on a willingness to empathize and a willingness to help others. Through cinema stories, students can find many models that can provide many examples of prosaically habits and verbally expressed feelings of empathy.

Third, the level of behavior of Cinema Use can guarantee personal freedom and protect students' secrets because usually students are afraid and anxious to open personal things such as bad habits and unpleasant experiences that have been experienced. At this stage students are invited to reflect the content of the cinema story that has just been seen, discuss about the good and bad characters in the story, the moral message that can be taken, how the characters feel in the story, and what examples can be taken from the main character, so as to increase students' awareness of the importance of empathy towards others.

On an emotional level, individuals can get carried away with their feelings and develop awareness regarding emotional insights, increase empathy, and foster altruistic attitudes in students. Through this stage, students become emotionally involved in the story of cinema and channel the emotions that are buried in him safely. In this process students are able to unload their emotional burdens and relieve emotional distress.

\subsection{Cyberbullying Preventive Strategies Through Cinema}

Cyberbullying prevention using cinema is done through cinema therapy activities. Cinema therapy is a therapy technique that uses film to get the meaning of the process of guidance and counseling to the counsel about the ability to look at them self or other individuals.

To carry out cinema therapy can be reached by several stages. In Cinema therapy there are the following steps:

\subsubsection{The Brief}

Preparing or drawing up instructions helps individuals to prepare them. It can also help individuals to capture their impressions, and be able to remember their process in a movie watching session. In these instructions can be recommended such as; to stay comfortable in watching, paying attention to the position of the body, regulating breathing in order to release tension, and a little bit of personal reactions that form.

\subsubsection{Movie Selection}

Films can be hand-selected by individuals or groups or by practitioners. Selected movies/videos should provide a more insightful, insightful or useful one. Counselors should choose movies that can be customized individual situations, problems, needs, and goals. Furthermore, other considerations are diversity issues such as background and culture. The selected film must have a storyline regarding the impact of bullying received by person. Film selection should avoid inappropriate content, such as harassment, violence, or other content that is potentially offensive or contrary to therapeutic purposes.

\subsubsection{Homework Assignments}

The use of homework has proven to be a useful technique in therapy. Setting a major movie as homework is well acceptable because watching a movie is considered a fun activity, and viewing can be done alone or together or in groups. Therapists should invite together to discuss how to react to the film. Individuals can write their reactions in the form of notes for use in shared discussions.

\section{CONCLUSION}

The prevention of cyber bullying using cinema is a preventive effort through the suppression of empathy. The use of cinema focuses on four aspects, namely intellectual, social, behavior, and emotional. Operationally, cyber bullying prevention using cinema follows the steps of cinema therapy, namely the brief, film selection, and home assignments.

\section{REFERENCES}

[1] B. Hamuddin, S. Syahdan, K Kurniawan. Cyberbullying on Students' Blog: Exploring Bully in Digital Era. ELT-Lectura, 5 (2) 165-170. DOI : https:// doi.org/10.31849/elt-lectura.v5i2.1700

[2] T. Wiguna, R. I. Ismail, R. Sekartini, N. S. W. Rahardjo, F. Kaligis, A. L. Prabowo, R. Hendarmo. The gender discrepancy in high-risk behaviour outcomes in adolescents who have experienced cyberbullying in Indonesia. Asian journal of psychiatry, 37 (2018) 130135. DOI : https://doi.org/10.1016/j.ajp.2018.08.021 
[3] F. S Rahayu. Cyberbullying sebagai dampak negatif penggunaan teknologi informasi. Journal of Information Systems, 8 (1) (2012) 22-31. DOI: https://doi.org/10.21 609/jsi.v8i1.321

[4] A. Julius, I. Fahriza, P. Wulandari. Digital Literacy As A School Counselor Competence In The Development Of Media In Guidance Services. Jurnal Penelitian Bimbingan Dan Konseling, 5 (2) (2020) 5060

[5] M. Kadivar, M. K. Mafinejad, J. T. Bazzaz, A. Mirzazadeh, Z. Jannat. Cinemedicine: Using movies to improve students' understanding of psychosocial aspects of medicine. Annals of medicine and surgery, 28 (2018) 23-27. DOI : https://doi.org/10.1016 /j.amsu.2018.02.005

[6] T. Wijaya Mulya, A. Aditomo. Researching religious tolerance education using discourse analysis: a case study from Indonesia. British Journal of religious education, 41 (4) (2019) 446-457. DOI : https://doi.org/ $10.1080 / 01416200.2018 .1556602$

[7] A. Khusumadewi, Y. T. Juliantika. The effectivene ss of cinema therapy to improve student empathy. In 2nd International Conference on Education Innovation (ICEI 2018) (pp. 566-569). Atlantis Press, 2018. DOI : https://doi.org/10.2991/icei-18.2018 .124

[8] D. M. Doumas, A. Midgett. Witnessing cyberbullying and internalizing symptoms among middle school students. European Journal of Investigation in Health, Psychology and Education, 10 (4) (2020) 957-966. DOI : https://doi.org/10.3390/ejihp e10040068

[9] C. D. Wiretna, W. N. E. Saputra, A. Muarifah, M Barida. Effectiveness of Solution-Focused Brief Counseling to Reduce Online Aggression of Student. Universal Journal of Educational Research, 8 (3) (2020) 1092-1099. DOI : 10.13189/ujer.2020.08034 4

[10] A. Ioannou, J. Blackburn, G. Stringhini, E. De Cristofaro, N. Kourtellis, M. Sirivianos. From risk factors to detection and intervention: a practical proposal for future work on cyberbullying. Behaviour \& Information Technology, 37 (3) (2018) 258-266. DOI : https://doi.org/10.1080/0144929X.2018.1432688

[11] J. M. Machimbarrena, E. Calvete, L. FernándezGonzález, A. Álvarez-Bardón, L. Álvarez-Fernández, J. González-Cabrera. Internet risks: An overview of victimization in cyberbullying, cyber dating abuse, sexting, online grooming and problematic internet use. International journal of environmental research and public health, 15 (11) (2018) 2471. DOI : https://doi.org /10.3390/ijerph15112471

[12] M. J. Wang, K. Yogeeswaran, N. P. Andrews, D. R. Hawi, C. G. Sibley. How common is cyberbullying among adults? Exploring gender, ethnic, and age differences in the prevalence of cyberbullying.Cyberpsy chology, Behavior, and Social Networking, 22 (11) (2019) 736-741. DOI : https://doi.org/10.1089/cyber.20 19.0146

[13] A. Mufiqoh, D. Y. P. Sugiharto, C. T. Anni. The Effectiveness of Group Guidance with Film Media to improve Students' Empathy and Social Interaction. Jurn al Bimbingan Konseling, 7 (2) (2018) 96-100. DOI : 10.15294/JUBK.V7I2.24390

[14] P. G. Blasco, G. Moreto, L. Pessini. Using Humanities to Promote Empathy and Encourage Ethical Attitudes: A GREFaculty Development Symposium. The Journal of Hospital Ethics, 6 (1) (2019) 67-67.

[15] R. Yulitri, E. Hardi. Profil Perilaku Altruistik Mahasiswa dan Implikasinya terhadap Program Pelatihan Kompetensi Kepribadian Calon Konselor. JKI (Jurnal Konseling Indonesia), 5 (2) (2020) 39-46. DOI : https://doi.org/10.21067/jki.v5i2.4363 